\title{
ASPECTS OF NAMING AND NAMES OF ASPECTS*
}

The paper undertakes an analysis of the discussion about the presence and varieties of the de dicto / de re ambiguity for names. I will argue that we are dealing with several phenomena here, which are relatively easy to confuse: first, usual de re; second, a name being normally used as opposed to being used as in a diverging or underdeveloped dialect; third, the reinterpetation of a name as denoting a (temporal, cognitive, etc.) aspect of an individual. The second and the third phenomenon can combine with usual de re.

After surveying the examples, I first filter out those in which deviant dialects are manifest. This issue is resolved via a diagonalisation operation across the special dimension called "dubbing-in-force", which is essentially the part of the naming conventions salient in the discourse situation. Then the cases of semantic reinterpretation are considered, where I stipulate the existence, on a par with the usual domain of individuals, of a dedicated domain of aspect-type entities to which a name can refer in some cases. This stipulation does not by itself destroy rigid designation, as names continue to denote rigidly, even if what they denote is aspects of individuals rather than complete individuals. Finally, I turn to customary de re readings for singular terms, where the difference between the aspect/individual contrast and the de re / de dicto ambiguity is emphasised; I provide a Quinean "double vision" scenario which, unlike the original version, involves aspects of individuals. Thus the possibility of superposition is demonstrated for the phenomena studied in the paper. Refs 25 .

Keywords: de re, de dicto, formal semantics, attitude reports, rigid designators, double vision, aspects, diagonalisation.

\section{B. Tiskin}

\section{АСПЕКТЫ ИМЕНОВАНИЯ И НАИМЕНОВАНИЯ АСПЕКТОВ}

Статья посвящена дискуссии о существовании и разновидностях неоднозначности между чтениями de re и de dicto для имен собственных. Показано, что речь здесь должна идти о нескольких явлениях, которые не следует смешивать: с одной стороны, о de re как таковых; с другой стороны, о диалектных или идиолектных различиях в употреблении имен; наконец, о возможной реинтерпретации имен, в результате которой они обозначают (временные, перцептивные или иные) аспекты индивидов. И диалектные различия, и реинтерпретация могут сочетаться с чтением de re для того же самого имени в том же самом контексте.

Вначале рассматриваются примеры диалектных различий. Для решения этой проблемы вводится операция диагонализации, затрагивающая, в противоположность ее классическому применению у Р.Столнейкера, особый семантический параметр - «действующую конвенцию» (dubbing-in-force), которая представляет собой принятый в данной коммуникативной ситуации набор значений имен. Затем мы обращаемся к случаям, в которых происходит реинтерпретация, где предлагается ввести, наряду с доменом самих индивидов, особый домен индивидных аспектов, к которым иногда могут отсылать имена. Таким образом, удается предложить общую трактовку для высказываний о пропозициональных установках и высказываний с временной модальностью. При этом нет необходимости отказываться от теории жесткой десигнации (С. Крипке), поскольку имена могут жестко обозначать аспекты индивидов. Наконец, мы касаемся чтений de re в собственном смысле, подчеркивая различие между ними и способность отсылать к индивиду (а не к его аспекту); для этой цели приводится сценарий, сконструированный по модели случаев «двойного знакомства» (double vision) У.В.О.Куайна,

Тискин Даниил Борисович - аспирант, Санкт-Петербургский государственный университет, Российская Федерация, 199034, Санкт-Петербург, Университетская наб., 7-9; daniel.tiskin@gmail.com

Tiskin Daniel B. - Postgraduate, Saint Petersburg State University, 7-9, Universitetskaya nab., St. Petersburg, 199034, Russian Federation; daniel.tiskin@gmail.com

* Research supported by the Russian Foundation for Humanities, project no. 14-03-00650.

(c) Санкт-Петербургский государственный университет, 2016 
с тем отличием, что место знакомства с индивидом в нем занимает знакомство с аспектом. Это показывает возможность сочетания нескольких явлений из исследуемой группы, вносящих совместный вклад в семантику высказывания. Библиогр. 25 назв.

Ключевые слова: de re, de dicto, формальная семантика, высказывания об установках, жесткие десигнаторы, «двойное знакомство», аспекты, диагонализация.

When Frege [1] formulated his now classical puzzles about informativeness and substitutivity of coreferential terms, only the semantic differences arising from substitution could be surprising; the fact that it was names (as opposed to any other expressions with intuitively clear meaning) that caused the substitution problems was not especially problematic. Indeed, it was not until Kripke [2] that the view on names as rigid designators became conventional. On that view (put in somewhat formally biased terms), the denotation of a name does not co-vary with the possible world index introduced by a modal operator, be it an alethic or an epistemic/doxastic predicate. That is, not only

(1) Aristotle might have failed to become Plato's student.

cannot mean 'in some possible world, the person called Aristotle in that world does not study under Plato'; but also

(2) Mary believes that Aristotle was not Plato's student.

cannot have the meaning 'in the worlds compatible with what Mary believes: the person called Aristotle in those worlds does not study under Plato'. (For the possible world semantics for belief, see Hintikka [3].)

This claim has been repeatedly put into doubt ever since. In Section 1, I review the problems that have been pointed out. In Section 2, a sub-group of problematic cases is treated separately as involving diagonalisation-like operations. Section 3 reviews the analyses proposed so far for the remaining puzzles and outlines my proposal in terms of aspects of individuals, as opposed both to individuals themselves and to modes of presentation thereof. Finally, Section 4 ties a loose end by providing a mechanism for de re that can be superposed onto the aspectual semantics.

\section{The range of explananda}

One group of problematic cases is constituted by Fregean identity puzzles, sometimes complicated with what prima facie looks like contradiction but actually is not (3):

(3) Thales believes that Hesperus is shining and disbelieves that Phosphorus is shining $[4,304]$.

This sentence is true if Thales believes Phosphorus and Hesperus are names of different objects. Pelczar and Rainsbury [4] observe that (3) would be infelicitous with believes in both cases replaced with said; so it would be wrong to assimilate cases like (3) into the realm of quotation.

Saul Kripke himself also contributed to the study of such deviant examples. As Hintikka and Sandu [5] indicate, Kripke's "Puzzle about Belief" [6] may be viewed as a defeatist proclamation of a rigidity theorist, where it is acknowledged that rigid designation theory does not fare well w.r.t. "agentive" modalities such as knowledge and belief.

Some theorists have a strong tendency to interpret cases like (3) as revealing something about the rigidity problem. For instance, Hintikka and Sandu [5, p. 277] write: "If I do not see which of the two boys is Tim and which one is Tom, the proper names 'Tim' 
and 'Tom' will refer to different visual objects of mine in different possible situations compatible with my visual information, that is, these names are not rigid in the context of perspectival identification". As will be seen below, my view on the issue, together with a handful of other theorists, is different: one can remain agnostic about the rigidity (in the narrow sense) of proper names (pace the authors who insists that names are "deeply rigid" [7], i.e. cannot vary in denotation even in two-dimensional semantics) and still make sense of (3).

A related problem, also anticipated by Frege, is that of informativeness. Cf. e.g. the following scenario, based on Prior's [8]: there is a certain Mrs. Murphy, who believes everything she is told (unless it contradicts something she already believes). Once she is told the following:

(4) Johnny Jones has measles.

Mrs. Murphy has no idea who Johnny Jones is; so she can hardly be assumed to have acquired a belief regarding him. The question is, therefore, what is the new piece of information, if any, Mrs. Murphy has acquired upon the utterance of (4)?

Another group of problematic cases, superficially similar to (3), has been brought to attention by Saul [9] (which provoked a lively discussion, including contributions by Moore [10], Barber [11], Forbes [12], Pitt [13], Zimmermann [14], and Jespersen [15]). Consider the following pair of examples:

(5) Clark Kent went into the phone booth, and Superman came out.

(6) Superman went into the phone booth, and Clark Kent came out.

Despite the fact that, according to the fictional story, Kent and Superman are the same creature, (5) can be made perfect sense of: it means, roughly, that a person dressed and behaving as a newspaper reporter went into the booth and re-dressed there, so that he went out dressed as a superhero. In the same sort of situation, (6) would be at best misleading if at all acceptable. On the surface of it, however, (5) and (6) contain no intensional operators, so the lack of substitability of coreferential expressions is unexpected.

Finally, Asudeh \& Giorgolo [16] provide a pair of sentences they consider problematic for the analyses of (5)-(6) based on the distinction between "enlightened" and "ignorant" uses of Clark Kent and Superman, i.e. the uses purporting to reflect the speaker's knowledge of the identity or the lack of such knowledge.

(7) Lois Lane loves Clark Kent, but she does not love Superman.

(8) Lois Lane punched Clark Kent, but she did not punch Superman.

The example (7) can be interpreted in a non-contradictory way even if none of the conversation participants pretends as if she were ignorant of the real identity; on the contrary, (8) cannot be so interpreted and is not subject to any "charitable" reinterpretation (e.g. 'Lois' intention was to punch Kent, not Superman, as she thought they were distinct individuals').

\section{Diagonalisation as a last resort}

If one considers (3) more carefully, various hypotheses may arise as to where the source of anomaly resides. One version is that the naming conventions Thales uses are different from ours to the effect that Thales uses the two names coreferential in our dialect to refer to non-identical objects. But what exactly are those two objects then? They do not exist in our world otherwise than as represented by a single object, viz. the planet Venus. 
So irrespective of whether we claim a dialectal difference or not, there is some other difference anyway, namely whether there is one object Venus (as in the actual world) or two objects in its place (as in Thales' belief worlds). Moreover, in some intuitive sense the two non-actual objects exactly correspond to the two "aspects" of Venus - the heavenly body seen in the morning and that seen in the evening. This will be the topic of the next section; here I would like to present the dialectal variation problem in isolation.

Fortunately, the literature does contain clearer cases. One is due to Kamp [17], who argues that in a carefully arranged context (where it is clear that Bill takes Aldebaran to be the name of a certain artificial object, e.g. a satellite),

(9) Bill thinks that Aldebaran will be used until the 22nd century.

may be interpreted so as to ascribe to Bill an attitude towards the artificial object, not to the star (which probably cannot be used anyway). Here no "doubling" of an actual individual in Bill's belief worlds is involved, and one can clearly see the dialectal variation problem in its pure form. Another such case is in fact (4) as presented above: Mrs. Murphy has no chance to learn who Johnny Jones is, so her dialect (unlike probably that of the person who told her) is underspecified w.r.t. what Johnny Jones means (on a given occasion). (The predicativist literature is rather rich in cases of this kind. E.g. Bach [18] provides the sentence, Aaron Aardvark might have been president, intended to mean that if the elections were so arranged that the person whose name is first in the alphabetical list wins, then someone called Aaron Aardvark could win. Similarly, Groenendijk et al. [19] come up with the following discourse: Someone has done it. It might be Alfred. It might not be Alfred, whose possible meaning is 'This guy has done it, but the speaker is not sure if he is called Alfred.)

Superficially, this contradicts the rigidity thesis about proper names. However, more or less the same puzzle may be replicated when no proper names are involved: with the same amount of ingenuity as we needed to force the dialect-shifted interpretation of (9), one could force an interpretation of

(10) Bill thinks Mao was not a Communist.

under which (10) amounts to the following: 'Given what Bill thinks Communist means, he does not think Mao was that'. (Cf. also Asudeh \& Giorgolo's [16] ex. (96).)

This much said, a successful solution for (9), (10) and (given certain assumptions) for (3) should be general w.r.t. the types of the expressions subject to dialectal variation, and at the same time it must be kept apart from the rigidity issues. The general idea of such a solution is to make the interpretation function $\|$.$\| take an additional argument, which in turn$ will be manipulated by the denotation of the propositional attitude verb or depend on the name of the attitude holder. One possible implementation would be, following the spirit of Asudeh \& Giorgolo [16] and the approach to quotation in Shan [20], to make the interpretation function take the attitude holder index, so that the semantics of (9) amounts to

(9') For all worlds $w$ compatible with what Bill believes at the actual world @: $\|$ Aldebaran $\|^{\text {Bill }}$ is used until the 22nd century at $w$.

Thus for the full interpretation of (9) one would have to know the value of $\|$ Aldebaran $\|^{\text {Bill }}$, i.e. to know which object Bill calls Aldebaran. Without this piece of knowledge, the interpretation would be incomplete. Moreover, the question I posed in connection with (4) would remain largely unanswered: there is no particular denotation of Johnny Jones for Mrs. Murphy, so (4) will remain uninterpreted for her. Intuitively, however, she does extract some information out of (4). 
A more plausible way in this regard is to make use of diagonalisation. This technique makes sense in a two-dimensional semantics, where the denotation of an expression depends on two world indices - the world of the evaluation $w$ and the world $w_{c}$ where the meanings of the terms are fixed. (Normally meanings are fixed in the world of utterance, which is the actual world @ in the cases we consider.) The diagonalisation operator $\dagger$ makes an expression whose denotation depends on the pair $\left\langle w, w_{c}\right\rangle$ (for some $w_{c}$ ) depend on $\langle w, w\rangle$ instead (see Stalnaker [21]). Here are the "logical form" and the truth-conditions for (9) in such a framework:

(9") Bill thinks [ [ $\dagger$ Aldebaran] will be used until the 22nd century].

(9"') For all worlds $w$ compatible with what Bill believes at the actual world @: $\|$ Aldebaran $\|^{w, w}$ is used until the 22 nd century at $w$.

The part $\|$ Aldebaran $\|^{w, w}$ reads: "the $w$-fixed denotation of Aldebaran in $w$ ", or, informally, "whatever Aldeberan refers to at $w$ if its meaning is fixed at $w$ itself". Given this, the informational contribution of (4) for Mrs. Murphy becomes clear: it is, roughly, 'Our world is one of worlds $w$ s.t.: the individual called Johnny Jones at $w$ has measles at $w$ '. Unlike under the holder index approach, this is the complete interpretation of (4).

So far, so good; one final improvement is in order. Kaplan [22] has suggested a constraint on natural language design widely cited as Prohibition against Monsters:

(11) There are no "monsters" in natural languages, i.e. there is no operator $\Delta$ changing the context of evaluation: $\|\Delta \phi\|^{w, c}=\|\phi\|^{w, c^{\prime}}$ for some $c^{\prime}$.

Our $w_{c}$ is essentially a part of the context, therefore postulating an occurrence of $\dagger$ goes against (11). Is there a way to retain the main intuitions behind (9")-(9"') and the proposed treatment of (4) without violating (11)? A hint in the right direction is found in Pelczar \& Rainsbury [4]. They suggest that the use of proper names (as opposed to e.g. common nouns, thus we have to put (10) aside) is governed by a separate parameter called "dubbing-in-force" and responsible for determining which dubbing conventions are currently employed. Thus, for instance, if I am talking to Mary, who has got a brother called John but is not aware that I too have a brother called John, Mary will interpret my use of the name John as governed by some dubbing-in-force that assigns her brother, not my brother, to the name John. If the interpretation function is made dependent on the dubbing parameter $d$, the information Mrs. Murphy receives with (4) may be rendered as

(4') For some $d$ : $\|$ Johnny Jones $\|^{d}$ has measles.

A violation of (11) is thus avoided.

\section{Aspects and naming}

From now on, all the complications related to diagonalisation and dubbings-in-force will be sidestepped. We shall focus on a different problem, namely the proper analysis of (5)-(8) and of (3), to the extent the latter has not yet been covered.

The discussion initiated by Saul [9] centered on cases like (5) and (12).

(12) I never made it to Leningrad, but I visited St. Petersburg last week.

The intuitive meaning of (12) is, of course, that the speaker had never been to the city during the period when it was called Leningrad but visited it later. However, this does not follow from the standard semantics for proper names, whatever stance on rigidity one takes: nothing like time or tense is usually taken to be relevant for the denotation of names. 
Aspects. The idea that Leningrad and St. Petersburg may refer to different temporal phases of the same object is present already in Saul's paper. Similarly, in (3) Hesperus and Phosphorus may pick up different temporal phases of the planet Venus, this time discontinious: every morning the planet appears as Phosphorus, to "turn into" Hesperus in the evening, and so on.

As regards Superman and Clark Kent, the simplest idea would be that the difference in meaning between the two names boils down to the attire the named individual wears, to the effect that he is called Superman when dressed in the superhero style and Kent when dressed ordinarily. This simple view encounters certain difficulties (Barber [11], Saul [23]), which, however, do not seem totally insuperable; perhaps more importantly, Zimmermann [14] suggests that Clark Kent is more restricted in its use than Superman: while the latter can name the relevant individual all the time, the former is confined to the occasions when he is dressed as a reporter.

A more general approach able to encompass either (5) and its kin or (12) treats either temporal stages of the city or "attire stages" of Superman/Kent as aspects, which may even be viewed as ontologically prior to individuals themselves (cf. Moore [10], Pitt [13]). Complete individuals are then sums of aspects.

There may be disagreement, however, as to how exactly aspect dependence should be formalised. In theory, the restrictions on the use of names may be rendered as definedness conditions (e.g. visit Leningrad is defined iff the time of the visit overlaps with the period when the city bore its Soviet name; Clark Kent went out is defined iff at the moment he was dressed as a reporter) or as a full-fledged part of the semantics (e.g. visit Leningrad denotes the property of visiting the city during the period when it bore its Soviet name, and Clark Kent went out is true iff Superman/Kent went out dressed as a reporter). (As Pitt [13] notes, this is no threat to rigidity or direct reference: the name refers directly and rigidly, although not to the individual but to selected "slices" thereof.) I opt for the latter version; cf. e.g. the argument in Moore [10]: one is sometimes able to anaphorically refer to an aspect, such as in

(5') Clark Kent went into the phone booth, and Superman came out, but he didn't look happy, unlike Clark.

Let us introduce a new semantic type for aspects, called $\bar{e}$, on a par with the type of individuals $e$. So there can be predicates that need $\bar{e}$-type arguments on a par with those satisfiable by $e$-type ones. Let $x, y, \ldots$ be variables over individuals and $a, a^{\prime}$ etc. be variables over aspects, and let $\subset_{w}$ be the relation which holds at the world $w$ between an aspect and the complete individual this aspect belongs to. (We will see in the next section how both types $\bar{e}$ and $e$ are employed to capture the difference between (7) and (8).) Aspects may overlap or include one another; for each individual $x$ and each world $w$ there is the maximal aspect corresponding to $x$ at $w$; in that world the maximal aspect includes all other aspects there are for $x$. For instance, the maximal aspect of the city of St. Petersburg includes its Leningrad aspect and its St. Petersburg aspect, alongside with the Petrograd aspect.

At this point we can formulate the denotations for the names we encountered so far:

(13) a. $\|$ Superman $\|^{w}=\mathrm{t} a . a \subset{ }_{w} \mathbf{s}$

b. $\|$ Clark Kent $\|^{w}=$ เa. $a \subset{ }_{w}$ s \& Reporter-attired $(a)$

(14) a. $\|$ St. Petersburg $\|^{w}=$ เa.a $a{ }_{w} \mathbf{c}$

b. $\|$ Leningrad $\|{ }^{w}=$ เa. $a \subset{ }_{w}$ c \& Between-1924-and-1991(a) 
Note that, although the denotation of a name depends on the world parameter, the semantics contains reference to a complete individual (s for Superman or $\mathbf{c}$ for the city of St. Petersburg), and w.r.t. that individual the name is a rigid designator. (Technically, the denotation of Superman must be the maximal aspect $a$ satisfying $a \subset_{w} \mathbf{s}$, because otherwise the denotation of Clark Kent, an aspect which is included into the denotation of Superman, would be an equally good candidate. To incorporate this consideration, just read $\mathrm{t}$ as the maximalising operator.)

Identity statements. For Pitt [13], who assumes something similar to the ontology of aspects (under the name of "alter egos"), sentences like

(15) Superman is Clark Kent.

are literally false, as they assert the identity of literally distinct aspects (that they are distinct is easily seen from (13)). Like Saul [9] and Jespersen [15] and pace Pitt [13], I do not think the literal truth is in this case "negotiable"; there are several ways to preserve it. First, one may claim that names of aspects are systematically ambiguous between an aspect reading and a reading under which they denote the actual individuals whose aspect this is. Alternatively, the copula is may take aspect names as arguments but check, instead of aspect identity, the identity of the complete individuals at the world of evaluation (something loosely similar has been proposed by Jespersen [15]):

(16) $\|i s\|^{w}=\lambda a \cdot \lambda a^{\prime} . \iota x\left(a \subset_{w} x\right)=\imath y\left(a^{\prime} \subset{ }_{w} y\right)$.

Pragmatic reinterpretation. As defined above, Superman is applicable either to reporter-slices or to superhero-slices of the individual Kent/Superman. (This is in accordance with Zimmermann's [14] suggestion.) However, in (5) and (6) Superman is contrasted with Clark Kent, which according to (13) denotes an aspect fully included into Superman. How is that possible? One solution is suggested by Pitt [13], who claims that neither Superman nor Clark Kent captures the maximal aspect of Superman/Kent; another solution, to which I stick, is to assume that in a suitable context, the less restricted name Superman may be pragmatically narrowed, yielding

(13) a'. $\|$ Superman $\|^{w}=$ เa. $a \subset_{w}$ s \& Reporter-attired $(a)$

or

(13) a". $\|$ Superman $\|^{w}=$ เa.a $a{ }_{w}$ s \& Superhero-attired $(a)$.

\section{Aspects in attitude reports}

Let us now turn to (7)-(8). Unlike the fully extensional (8), (7) exemplifies an attitude context, albeit not that of a propositional attitude. It is instead an objectual attitude report (cf. e.g. Forbes [12]), that is, a report of an attitude an agent has towards a (specific or unspecific, imaginary or real) individual. Here we are dealing with a simple case, where the object of the attitude is specific and real. However, the opacity (non-substitutivity) of the attitudinal context is apparent anyway: to love Clark Kent does not mean to love Superman, and vice versa.

Aspects in objectual attitude reports. Apart from Pelczar \& Rainsbury [15]-like indexical parametrisation, a route leading to non-substitutivity is to bring some quotational flavour into the semantics of objectual attitude reports. This would circumvent the rigidity of names and prohibit substitution, and this is essentially what Forbes [12] goes for. In his view, an attitude report may optionally contain a silent demonstrative element so that refers to the particular way the object of the attitude is picked out. (This requires some 
technical work, which Forbes does, because to refer to words themselves is not a common ability for demonstratives.) For instance, the semantics for (17) in Forbes' terms would be somewhat like in (18).

(17) Lois Lane loves Clark Kent.

(18) เa.Labelled $\left(\alpha, s o_{i}\right)$ : UNDER $\left(\alpha, \operatorname{Loves}\left(\mathbf{1}, \mathbf{k}_{i}\right)\right)$

This means, first, that Lois loves the (complete) individual Superman/Kent and, second, that the way of thinking a about Superman/Kent relevant for Lois' love is labelled k, i.e. Lois loves Superman/Kent under the guise that is named Clark Kent, not the one named Superman.

Why is the demonstrative optional? The reason is that, especially given a suitable context (e.g. one where Superman is contrasted with Batman or the mayor of Metropolis), the situations in which (7) and (17) are true can be nevertheless described using (19).

(19) Lois Lane loves Superman.

Without Forbes' hidden demonstrative so, (19) claims no more than that Lois is in love with the individual Superman/Kent, whatever her ways of thinking of him may be. The position of Superman in (19) is then fully transparent, so Clark Kent and Superman are intersubstitutable there.

Forbes' semantics is rather complicated; the view on names as referring to aspects familiar from Section 3 comes in handy here. The meaning Forbes would express as (18) may be put just as

$\left(18^{\prime}\right)$ Loves $\left(\mathbf{l},\left[\right.\right.$ เ $a . a \subset{ }_{w} \mathbf{s} \&$ Reporter-attired $\left.\left.(a)\right]\right)$

according to the denotation of Clark Kent in (13). Therefore, we must stipulate that love takes an aspect (type $\bar{e}$ ) as its "lovee" argument, whereas its "lover" argument is a complete individual. In this sense, loving an aspect does not guarantee loving any other aspect of the same complete individual, even if the latter aspect is included into or includes the former (as it is with Superman and Clark Kent according to (13)). As long as punch in (8) is not sensitive to differences in aspect, we likewise stipulate that punch takes a complete individual (type $e$ ) as the "punchee" argument as well.

Aspects and de re. This may already look like "the" de dicto / de re ambiguity available for (17) and (19); however, as noted already by Jespersen [15], "[i]t is the ascriber, and not the ascribee Lois, who is responsible for using the names 'Superman' and 'Clark Kent'. The ascription need not presuppose, in order to be true, that Lois know either name". If the position of Superman / Clark Kent is fully transparent, whether or not Lois knows the names makes no difference (as with any de re reports, cf. Quine's [24]). However, if the position is sensitive to the way of thinking (as in (18)), there is a difference: either (a) Lois knows the name Clark Kent and would say to herself, "I love Clark Kent", or (b) she does not know the name although her feelings are clearly directed towards the reporter aspect of the individual Kent/Superman (and she may fail to know that Kent is Superman). It is (b) that we traditionally call de re w.r.t. propositional attitude reports.

Moreover, what if we try to reproduce Quine's [24] double vision puzzle with aspects? Imagine that Lois is under the common but wrong impression that Superman is not the same individual as Clark Kent; she is in love with Kent, whom she knows rather well, but not with Superman. She definitely does not think, "Clark is a spy". As for Superman, once she sees him sneaking around the docks wearing his superhero attire. In the darkness she is only able to tell him apart from Kent, but she fails to realise she has seen the renowned superhero. Are we not inclined to judge (20a), (20b) and (20d) true and (20c) false under this scenario? 
(20) a. Lois Lane thinks Superman is a spy.

b. Lois Lane thinks Superman is not a spy.

c. Lois Lane thinks Clark is a spy.

d. Lois Lane thinks Clark is not a spy.

If we are, one might reasonably speak of different ways of thinking about an aspect much in the same way one usually speaks of ways of thinking about an individual (as in Quine's paper). Therefore, even apart from diagonalisation (see Section 2), we need more than one semantic device to account for the data on names in attitude reports. One device is that of reference to aspects (ways of thinking); it may be employed in a given sentence ((7) and (17)) or not ((8) and (18)). Another is some mechanism that generates de re readings; similarly, it may be employed (as in (20)) or not, irrespective of whether reference is made to aspects or to complete individuals.

Now we can get back to (3). Perhaps the most natural reading for it is as follows: 'Thales does himself use the names Phosphorus and Hesperus, by which he refers to the morning aspect and to the evening aspect of what we know to be a single object; of those two aspects he believes that the first one is shining and the second is not.' This is aspect reference without de re. I do, however, think that (3) can also have a de re reading w.r.t. Phosphorus and Hesperus even when aspect reference is preserved. The prerequisite for such a reading would be that for the speaker and her audience the names Phosphorus and Hesperus be firmly associated with the two aforementioned aspects, and that Thales have beliefs about those two aspects even though he does not happen to use the very same names.

\section{Conclusion}

In this paper I have made several claims. First, the observably complex behaviour of proper names in indirect contexts is best viewed as resulting from the interaction of several semantic modules. One of them, probably not limited to names but rather restricted in distribution, is "last resort" diagonalisation, which comes into play when it is impossible to construe a name as having its usual denotation. The remaining two modules are reference to aspects instead of complete individuals and the de re reading of a name. The former normally shows up in the contexts of "agent-involving" modality such as belief or desire, i.e. in attitude reports as opposed to necessity, possibility, analyticity etc. The latter is an instance of a more general mechanism that also applies to terms in alethic modal contexts.

I have remained silent in the present paper about the details of the semantics for de re. They are indeed of lesser importance once the division of labour between semantic modules is acknowledged. As for particular implementations, the concept generator theory first outlined by Percus and Sauerland [25] would suffice for many cases of propositional attitude reports if a generator were allowed to take an aspect - just as well as a complete individual - as its argument. Some adjustments are needed to handle objectual attitude reports, as the latter, unlike propositional attitude reports, are not universally assumed to quantify over possible worlds. (The view that they do is called propositionalism, cf. [12, pp. $148 \mathrm{ff}$.].) One way for a non-propositionalist to proceed is to claim that verbs like love take aspect (and not propositional) arguments but trigger a presupposition to the effect that the aspect is believed by the lover to be the maximal aspect corresponding to some individual; this presupposition is, as any presupposition in general, a proposition, so concept generators may be applied there. 


\section{References}

1. Frege G. Sense and reference. The Philosophical Review, 1948, pp. 209-230.

2. Kripke S. Naming and necessity. Harvard University Press, 1980.

3. Hintikka J. Knowledge and belief: an introduction to the logic of the two notions. Ithaca, Cornell University Press, 1962.

4. Pelczar M., Rainsbury J. The indexical character of names. Synthese, 1998, vol.114, no. 2, pp. 293-317.

5. Hintikka J., Sandu G. The fallacies of the new theory of reference. Synthese, 1995, vol. 104, no.2, pp. $245-283$.

6. Kripke S. A puzzle about belief. Meaning and Use. Springer, 1979, pp.239-283.

7. Rami D. On the unification argument for the predicate view on proper names. Synthese, 2014, vol. 191, no. 5, pp. 841-862.

8. Prior A. N. Oratio oblique. Proceedings of the Aristotelian Society, 1963, vol.37, pp. 115-126.

9. Saul J. Substitution and simple sentences. Analysis, 1997, vol. 57, no. 2, pp. 102-108.

10. Moore J. Saving substitutivity in simple sentences. Analysis, 1999, vol.59, no. 262, pp.91-105.

11. Barber A. A pragmatic treatment of simple sentences. Analysis, 2000, vol. 60, no. 268. pp. 300-308.

12. Forbes G. Objectual attitudes. Linguistics and Philosophy, 2000, vol.23, no. 2, pp. 141-183.

13. Pitt D. Alter egos and their names. The Journal of Philosophy, 2001, vol. 98, no. 10, pp. 531-552.

14. Zimmermann T.E. What's in two names? Journal of Semantics, 2005, vol. 22, no. 1, pp. 53-96.

15. Jespersen B. The phone booth puzzle. Organon F., 2006, vol. 13, pp.411-438.

16. Asudeh A., Giorgolo G. Perspectives. Ms., 2015.

17. Kamp H. Using proper names as intermediaries between labelled entity representations. Erkenntnis, 2015, vol. 80, Supplement 2, pp. 263-312.

18. Bach K. What's in a name. Australasian Journal of Philosophy, 1981, vol. 59, pp. 371-386.

19. Groenendijk J., Stokhof M., Veltman F. Coreference and modality. The Handbook of Contemporary Semantic Theory, 1996, pp. 179-216.

20. Shan C.-C. The character of quotation. Linguistics and Philosophy, 2010, vol.33, no. 5, pp. 417-443.

21. Stalnaker R. Assertion. Pragmatics. New York Academic Press, 1978, pp. 315-332.

22. Kaplan D. Demonstratives. Themes from Kaplan. Oxford University Press, 1989, pp. 481-563.

23. Saul J. Reply to Forbes. Analysis, 1997, vol. 57, no. 2, pp. 114-118.

24. Quine W.V.O. Quantifiers and Propositional Attitudes. The Jou1nal of Philosophy, 1956, vol.53, no. 5 , pp. 177-187.

25. Percus O., Sauerland U. On the LFs of attitude reports. Proceedings of Sinn und Bedeutung, 2003, vol. 7, pp. 228-242.

For citation: Tiskin D. Aspects of naming and names of aspects. Vestnik SPbSU. Series 17. Philosophy. Conflict studies. Culture studies. Religious studies, 2016, issue 4, pp. 75-84.

DOI: $10.21638 / 11701 /$ spbu17.2016.408

Received: 22.05.2016

Accepted: 16.06.2016 